\title{
FITOTOXIDEZ E TAXA DE COBERTURA VERDE DE GRAMADO BERMUDA SUBMETIDO A DOSAGENS DE NITROGÊNIO E GLIFOSATO
}

\author{
PHYTOTOXIDITY AND GREEN COVERAGE OF BERMUDA LAWN SUBMITTED \\ TO NITROGEN AND GLYPHOSATE DOSAGES \&
}

\author{
FITOTOXICIDAD Y TASA DE COBERTURA VERDE DE GRAMADO BERMUDA \\ SOMETIDO A DOSIS DE NITRÓGENO Y GLIFOSATO 8
}

Recebido em: 19/08/2020 - Aprovado em: 11/12/2020 - Publicado em: 20/04/2021

http://dx.doi.org/10.18011/bioeng2021v15n1p27-41

Maria Clara Lelles Moreira Begueline1 (mariaclara_begueline@hotmail.com)

Leandro Garcia Alfonsi ${ }^{1}$ (lealfonsi@gmail.com)

Kamila Cristina de Credo Assis' ${ }^{1}$ (k.assis@unesp.br)

Leandro José Grava de Godoy ${ }^{1}$ (legodoy@registro.unesp.br)

João Victor Costa ${ }^{1}$ (joaovictor0796@hotmail.com)

${ }^{1}$ Faculdade de Ciências Agronômicas - FCA, Unesp Câmpus de Botucatu - SP, Brasil

\section{RESUMO}

O presente trabalho teve como objetivo avaliar dosagens de glifosato e de nitrogênio na taxa de cobertura verde e na taxa de fitotoxidez por imagem de gramado bermuda em condições tropicais. Adotou-se o delineamento experimental inteiramente casualizado com seis repetições. Os tratamentos foram feitos em esquema fatorial $4 \times 4$, sendo quatro subdoses de glifosato $\left(0,200,400\right.$ e $600 \mathrm{~g} \mathrm{ha}^{-1}$ do i.a.), e quatro doses de nitrogênio $\left(0,25,50\right.$ e $\left.100 \mathrm{mg} \mathrm{dm}^{-3}\right)$. O nitrogênio foi aplicado manualmente aos 27 dias após o plantio (DAP), com $100 \mathrm{ml}$ de solução de água com ureia, nas doses de 0,167, 333 e $667 \mathrm{mg}$ para cada $100 \mathrm{ml}$ de água. O glifosato foi aplicado com pulverizador manual de pressão prévia com pressão de trabalho de 45 psi. O herbicida utilizado foi o Roundup transorb, com i.a (glifosato) de $480 \mathrm{~g} \mathrm{~L}^{-1}$. Os percentuais de fitointoxicação foram determinados por imagens digitais conforme metodologia para taxa de cobertura verde. Foram avaliadas a taxa de cobertura verde e a taxa de fitotoxidez com o auxílio do software de imagens Corew Draw ${ }^{\circledR}$. Conclui-se que a subdose de glifosato que mais se adequou como fitorregulador de crescimento, foi a de $432 \mathrm{~g}$ ha- 1 juntamente com doses de $100 \mathrm{mg} \mathrm{dm}$ - 3 de nitrogênio para uma melhor qualidade do gramado. A aplicação do glifosato é viável no controle de crescimento do gramado bermuda desde que o mesmo apresente adubação eficiente em Nitrogênio. $O$ acréscimo de dosagens de nitrogênio propicia maior desenvolvimento do gramado bermuda.

Palavras-chave: Grama-Bermuda. Nutrição de Gramas. Regulador de Crescimento. Adubação.

Artigo publicado sob a licença Creative Commons - Atribuição 4.0 Internacional (CC BY 4.0). 


\section{INTRODUÇÃO}

A família na qual as gramas fazem parte é formada por mais de 10 mil espécies que estão distribuídas por todo o mundo. As mais conhecidas são utilizadas na alimentação humana, como exemplo está à cultura do arroz, milho e o trigo. As brachiarias, também pertencentes à família das gramas, são muito utilizadas na alimentação animal. Essas espécies são essenciais para o meio ambiente devido a produção de oxigênio, a absorção de gás carbônico, e além disso, possuem grande valor estético (GODOY; VILLAS BÔAS, 2010).

As gramas em geral são utilizadas há muitos anos para a formação de gramados, sendo que as espécies na sua maioria foram selecionadas a partir de pradarias e pastagens. Atualmente, os gramados utilizados são espécies híbridas com características melhoradas tanto visuais como de desenvolvimento, sendo necessário assim uma manutenção especializada. Dentre estes cuidados destaca-se a necessidade de aparas constantes da grama, fertilização, aeração do solo, irrigação e controle de plantas daninhas (GAZOLA, 2017).

Entre as espécies de grama mais comumente implantadas no Brasil estão as de clima quente, Santo Agostinho (Stenotaphrum secundatum), Bermuda (Cynodon spp), Zoysia (Zoysia spp), Centipede (Eremochloao phiuroides), Bahia ou Batatais (Paspa lumnotatum) e São Carlos ou Curitibana (Axono puscompressus), que se adaptam tanto as condições climáticas quanto ao intenso tráfego devido a rizomas que auxiliam na capacidade de regeneração do gramado (GURGEL, 2003).

A grama bermuda (Cynodon dactylon (L.) Pers) é de clima quente, originária no continente Africano, tem crescimento por rizomas e estolões, com grande densidade de folhas, e boa regeneração à injúrias (pisoteio), propagada via sementes ou por tapetes, "plugs" ou "sprigs", tolerância ao calor e à seca, porém possui baixa tolerância ao frio e ao sombreamento (LAURETTI, 2003).

$\mathrm{Na}$ adubação dos gramados, o macronutriente mais exigido é o nitrogênio. A alta disponibilidade de $\mathrm{N}$ proporciona crescimento da parte aérea das gramas, aumentando a densidade de folhas. Portanto, o $\mathrm{N}$ é essencial para acelerar a formação do tapete na produção de grama, assim como na formação de gramado a partir de "plugs" (GODOY et al., 2012). Porém, quantidades demasiadas do $\mathrm{N}$ promovem o crescimento da parte aérea, levando a um maior número de cortes (roçadas) (SANTOS, 2018). 
Os reguladores de crescimento vegetais quando utilizados em gramas podem reduzir a estatura das plantas sem prejudicar a densidade ou causar lesões visíveis ao gramado, como pontos necróticos de fitotoxicidade, coloração ou afinamento, mantendo a alta qualidade da área tratada. Dessa forma, tem-se diminuição de operações de corte, compreendido entre a primavera e o verão, atuando indiretamente como possível componente na redução de custos com mão-de-obra, combustível e equipamentos (SANTOS; CASTILHO, 2016).

Entre os reguladores de crescimento já utilizados em experimentação alguns trabalhos demonstram o potencial do uso de subdoses de herbicidas, como o glifosato (NEVES, 2009). O glifosato é um i.a de um herbicida não seletivo de ação sistêmica derivados da glicina. É absorvido via foliar e apresenta rápida translocação no interior da planta. No interior, inibe a fotossíntese, a síntese de ácidos nucléicos e estimula a produção de etileno (RODRIGUES, 1998).

O glifosato, quando utilizado em pequenas doses, ocasiona o equilíbrio da enzima EPSP sintase de forma a paralisar o crescimento da planta sem causar senescência ou morte, agindo como regulador de crescimento (OLIVEIRA JUNIOR, 2011).

Considerando os aspectos levantados o presente trabalho teve como objetivo avaliar dosagens de glifosato e de nitrogênio na taxa de cobertura verde e na taxa de fitotoxidez por imagem de gramado bermuda em condições tropicais.

\section{MATERIAIS E MÉTODOS}

O experimento foi conduzido em casa de vegetação da LOCAL (SP), cuja localização geográfica da área é de -24.5347894 de latitude S e -47.8610346 de longitude W. A casa de vegetação utilizada é do tipo arco, com $12 \mathrm{~m}$ de comprimento, $7 \mathrm{~m}$ de largura e pé direito de $3 \mathrm{~m}$, cobertas com polietileno de baixa densidade (PEBD) de $150 \mathrm{~mm}$.

Para melhor comparação com um gramado esportivo, utilizou-se areia como substrato. A análise do substrato foi realizada no Laboratório de Fertilidade do Solo do Departamento de Recursos Naturais/Ciência do Solo da Faculdade de Ciências Agronômicas /UNESP Campus-Botucatu, para determinação das características químicas, segundo (RAlJ et al. 2001) (Tabela 1). 
Tabela 1 - Características químicas substrato areia no cultivo de grama Bermuda (REGISTRO, SP, 2015).

\begin{tabular}{|c|c|c|c|c|c|c|c|c|c|c|c|}
\hline $\begin{array}{c}\mathrm{Ph} \\
\mathrm{CaCl}_{2}\end{array}$ & $\begin{array}{l}\text { M.O. } \\
\mathrm{g} \mathrm{dm}^{-3}\end{array}$ & $\begin{array}{c}P_{\text {resina }} \\
\mathrm{mg} \mathrm{dm}^{-3}\end{array}$ & $\mathrm{Al}^{3+}$ & $\mathbf{H}+\mathbf{A l}$ & $\mathbf{K}$ & $\begin{array}{r}\mathrm{Ca} \\
\mathrm{Imol}_{\mathrm{C}}\end{array}$ & $\underset{-3}{\mathbf{M g}}$ & SB & CTC & V\% & $\begin{array}{c}\mathrm{S} \\
\mathrm{Mg} \mathrm{dm}^{-3}\end{array}$ \\
\hline 5,6 & 6 & 14 & 0 & 9 & 0,8 & 10 & 3 & 13 & 22 & 59 & 5 \\
\hline
\end{tabular}

A espécie da grama escolhida para o trabalho foi a Bermuda (Cynodon dactylon (Pers) L.), uma das mais utilizadas em gramados esportivos, requer menos água que as outras variedades, possuem rápida recuperação, tolerância ao frio e densidade mais espessa.

Adotou-se o delineamento experimental inteiramente casualizado com seis repetições. Os tratamentos foram feitos em esquema fatorial $4 \times 4$, sendo quatro subdoses de glifosato $\left(0,200,400\right.$ e $600 \mathrm{~g} \mathrm{ha}^{-1}$ do i.a. $)$, e quatro doses de nitrogênio $(0,25,50$ e 100 $\mathrm{mg} \mathrm{dm}{ }^{-3}$ ). Utilizou-se para esse experimento vasos de polietileno com capacidade de 3 litros.

Com base no resultado da análise química (Tabela 1) em 23/09/2015 foram feitas as devidas correções de pH, para isso colocou-se em $432 \mathrm{~kg}$ de areia $500 \mathrm{~g}$ de calcário dolomítico apresentando 75 de PRNT, o que proporcionou aproximadamente $1,74 \mathrm{~g}$ de calcário por decímetro cúbico de areia, elevando a saturação de bases (V\%) para $70 \%$. Para que a reação fosse mais rápida colocou-se $4,5 \mathrm{~kg}$ do substrato com o calcário em sacos plásticos, e em seguida adicionou-se água deixando reagir por 20 dias.

Após os 20 dias de incubação, de acordo com a análise química (Tabela 1), no dia 14/10/2015 foi misturado ao substrato os fertilizantes Supersimples e Cloreto de Potássio sendo estes em doses de $10 \mathrm{~g} \mathrm{e} 720 \mathrm{mg}$, respectivamente, para elevar o P e K aos níveis de $250 \mathrm{mg}$ e $120 \mathrm{mg}$ por decímetro cúbico, respectivamente e então plantou-se os tapetes já cortados no diâmetro do vaso para a experimentação.

A irrigação foi realizada diariamente elevando os vasos até a capacidade de campo previamente obtida por ensaio.

O fator nitrogênio foi realizado manualmente aos 27 dias após o plantio (DAP), com $100 \mathrm{ml}$ de solução de água com ureia, nas doses de 0,167, 333 e $667 \mathrm{mg}$ para cada 100 $\mathrm{ml}$ de água. O fator subdose de glifosato foi realizado com pulverizador manual de pressão prévia com pressão de trabalho de $45 \mathrm{psi}$. O herbicida utilizado foi o Roundup transorb, com i.a (glifosato) de $480 \mathrm{~g} \mathrm{~L}^{-1}$. Aplicou-se 1,26 ml de calda por vaso aproximadamente $401 \mathrm{ml}$ de calda por hectare. 
Os percentuais de fitointoxicação foram determinados por imagens digitais conforme metodologia para taxa de cobertura verde de Godoy (2005). Foram selecionadas as cores com tonalidades bege ao invés das verdes, por meio da ferramenta "máscara de cor e histograma", as quais representam as lesões da fitointoxicação. A porcentagem de fitotoxidez foi baseada na escala da Sociedade Brasileira das Plantas Daninhas (SBCPD) (1995) que varia de "0" a "100", na qual o zero é ausência de injúria e "100" a morte total. O programa utilizado no tratamento das imagens digitais foi o Corel Draw Graphic Suite X6.

Utilizou-se as mesmas imagens digitais usadas para a determinação da intensidade de coloração verde, segundo metodologia de Godoy (2005). As imagens foram avaliadas individualmente utilizando-se o programa Corel Draw Graphic Suite X6. Esse programa permite a seleção e contagem dos pixels verdes da imagem, por meio da ferramenta "máscara de cor" e "histograma", respectivamente (Figura 8), podendo assim avaliar qual tratamento obteve melhor cobertura do substrato pelo gramado, com folhas vivas (verdes).

\section{RESULTADOS E DISCUSSÃO}

A interação das doses de nitrogênio com as subdoses de glifosato foi significativas aos 35 e 44 DAP (Tabela 2). Aos 35 DAP nos tratamentos que não receberam dose de nitrogênio, os resultados de fitotoxidez ajustaram-se de forma quadrática crescente onde a menor média encontrada foi de (0), quando não aplicado o glifosato, isso significa que o tratamento não obteve nenhuma injúria, já com uma subdose de $448 \mathrm{~g} \mathrm{ha}^{-1}$ de glifosato a média observada foi de $(25 \%)$, mostrando uma maior injúria causada pelo herbicida (glifosato) (Figura 1).

Com $25 \mathrm{mg} \mathrm{dm}^{-3}$ de $\mathrm{N}$ as médias dos tratamentos apresentaram resultados quadráticos crescentes, com ponto de máximo na subdose de $422 \mathrm{~g} \mathrm{ha}^{-1} \mathrm{embora}$ os valores observados nas doses de 200, 400 e 600 não diferiram muito entre si, (17.; 17; e 18\%, respectivamente). Para os tratamentos com $100 \mathrm{mg} \mathrm{dm}^{-3}$ de $\mathrm{N}$ e com as subdoses de glifosato mostraram médias quadráticas e observou-se os menores números de Ft, com a menor média observada quando aplicada 0 e $200 \mathrm{~g} \mathrm{ha}^{-1}$ de Glifosato $(0$ e 0,083). 
Tabela 2 - Resumo da análise estatística da fitotoxidez (Ft), aos 35, 44 e 52 DAP (REGISTRO, SP, 2015).

\begin{tabular}{cccc}
\hline & 35 DAP & 44 DAP & 52 DAP \\
Fator de Variação & & $\mathrm{Ft}$ & \\
Dose $(\mathbf{N})$ & & $\mathrm{p}$-valor & \\
Subdose $(\mathbf{G})$ & $<0,0001$ & $<0,0001$ & 0,0002 \\
$\mathbf{N} * \mathbf{G}$ & $<0,0001$ & $<0,0001$ & $<0,0001$ \\
$\mathbf{C . V .} \%$ & $<0,0001$ & $<0,0001$ & 0,3749 \\
Regressão $(\mathbf{N})$ & 21,68 & 27,80 & 36,61 \\
Regressão $(\mathbf{G})$ & $0,0194 \mathrm{Q}$ & $<0,0001 \mathrm{Q}$ & $0,0001 \mathrm{~L}$ \\
\hline C.V. - coeficiente de variação $(\%) ;$ DAP- dias após o plantio; $L$ e $\mathrm{Q}-$ linear e quadrático respectivamente.
\end{tabular}

Fonte: Autores, 2015.

A planta é submetida a processos fisiológicos, sendo o nitrogênio um nutriente essencial para a regulação do vegetal. Dentre esses processos estão a fotossíntese, a respiração celular, atividade das raízes, absorção iônica, diferenciação celular, entre outros. Com o manejo adequado desse nutriente, o crescimento da planta se torna contínuo, pois este nutriente está diretamente ligado à produção de novas células e tecidos (TAIZ et al., 2017). As altas dosagens de nitrogênio podem ter inibido parte do efeito fitotóxico do herbicida Glifosato.

Figura 1 - Fitotoxidez (Ft\%) de grama Bermuda em função das doses de nitrogênio dentro das subdoses de glifosato aos 35 DAP (REGISTRO, SP, 2015).

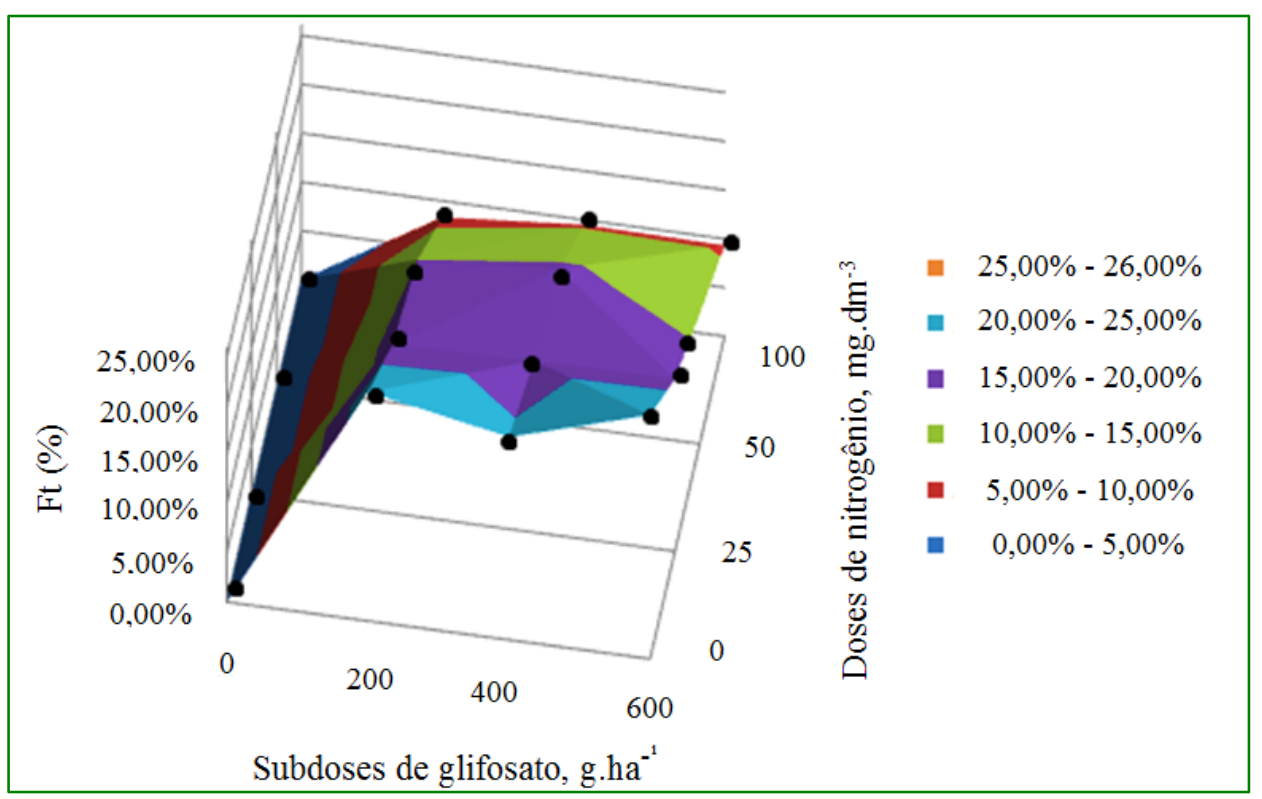

Fonte: Autores, 2015.

Ainda aos 35 DAP, quando os tratamentos não foram submetidos a subdoses de Glifosato, as médias para todas as doses de $\mathrm{N}$ foram (0) sem fitotoxidez, isso fez com que 
Fitotoxidez e taxa de cobertura verde de gramado bermuda submetido a dosagens de nitrogênio ...

os resultados fossem não significativos. Os resultados foram lineares para fitotoxidez para 200 e $400 \mathrm{~g} \mathrm{ha}^{-1}$ de glifosato e quadrático para $600 \mathrm{~g} \mathrm{ha}^{-1}$ nas dosagens de $\mathrm{N}$ (Tabela 3).

Tabela 3 - Doses de nitrogênio em função das subdoses de glifosato aos 35 DAP (REGISTRO, SP, 2015).

\begin{tabular}{|c|c|c|c|c|}
\hline Doses & & Máx & Min & Regressão \\
\hline 0 & $\hat{y}=0,016+0,001 x-1 E-06^{* * *} x 2$ & 448 & & $<0,0001 Q$ \\
\hline 25 & $\hat{y}=0,008+0,000 x-1 E-06^{* * *} x 2$ & 422 & & $<0,0001 Q$ \\
\hline 50 & $\hat{y}=0,005+0,000 x-1 E-06^{* * *} x 2$ & 400 & & $<0,0001 Q$ \\
\hline 100 & $\hat{y}=0,002+0,000 x-5 E-07^{* * *} x 2$ & 438 & & $<0,0001 Q$ \\
\hline \multicolumn{5}{|l|}{ Subdose } \\
\hline 0 & ns & & & ns \\
\hline 200 & $\hat{y}=0,22366672-0,00144572^{* * *} x$ & & & $<0,0001 \mathrm{~L}$ \\
\hline 400 & $\hat{y}=0,20811068-0,0011066^{* * *} x$ & & & $<0,0001 \mathrm{~L}$ \\
\hline 600 & $\hat{y}=0,248-0,003 x+2 E-05^{\star \star *} x 2$ & & 100 & $0,0012 Q$ \\
\hline
\end{tabular}

Observou-se que para aos 35 DAP as menores médias observadas foram quando submetidos a subdose de $200 \mathrm{~g} \mathrm{ha}^{-1}$ de herbicida. Resultados diferentes foram encontrados por Gazola et al. (2016) na grama esmeralda onde a dose de $400 \mathrm{~g} \mathrm{ha}^{-1}$ de glifosato foi insuficiente para demonstrar fitotoxidez no gramado.

Os tratamentos aos 44 DAP quando não foram submetidos a doses de $\mathrm{N}$ obtiveram resultados quadráticos, assim como aos 35 DAP a menor e maior médias observadas foram com as subdoses de 0 e $551 \mathrm{~g} \mathrm{ha}^{-1}$ de Glifosato (0 e $37 \%$ ) respectivamente.

Com doses de 25, 50 e $100 \mathrm{mg} \mathrm{dm}^{-3}$ de $\mathrm{N}$ nas subdoses de Glifosato, os resultados apresentaram-se quadráticos decrescentes, onde o menor resultado de Ft foi obtido a dose de $86 \mathrm{mg} \mathrm{dm}^{-3} \mathrm{com}$ a subdose de $400 \mathrm{~g} \mathrm{ha}^{-1}$ do i.a, (11\%) (Figura 2). Quando analisado cada subdose de Glifosato dentro das doses de N (Figura 2) observa-se que os tratamentos que não continham glifosato não foram significativos, devido as médias não apresentarem Ft.

Já para a subdose de $200 \mathrm{~g} \mathrm{ha}^{-1}$ de herbicida houve uma resposta linear decrescente, onde mostra que quanto maior a dose de $\mathrm{N}$ menor a Ft (Tabela 4). Com as subdoses de 400 e $600 \mathrm{~g} \mathrm{ha}^{-1}$ de $\mathrm{G}$, os resultados foram quadráticos decrescentes, também mostrando que quanto maior a dose e $\mathrm{N}$ menor a Ft. Aos 44 DAP diferentemente dos 35 DAP as menores médias observadas foram com os tratamentos que obtinham a subdoses de 400 
g ha-1 de Glifosato (Tabela 4). Observou-se também que aos 44 DAP houve um aumento de Ft comparado aos 35 DAP.

Figura 2 - Fitoxidez (FT\%) em função das doses de nitrogênio dentro das subdoses de glifosato aos 44 DAP (REGISTRO, SP, 2015).

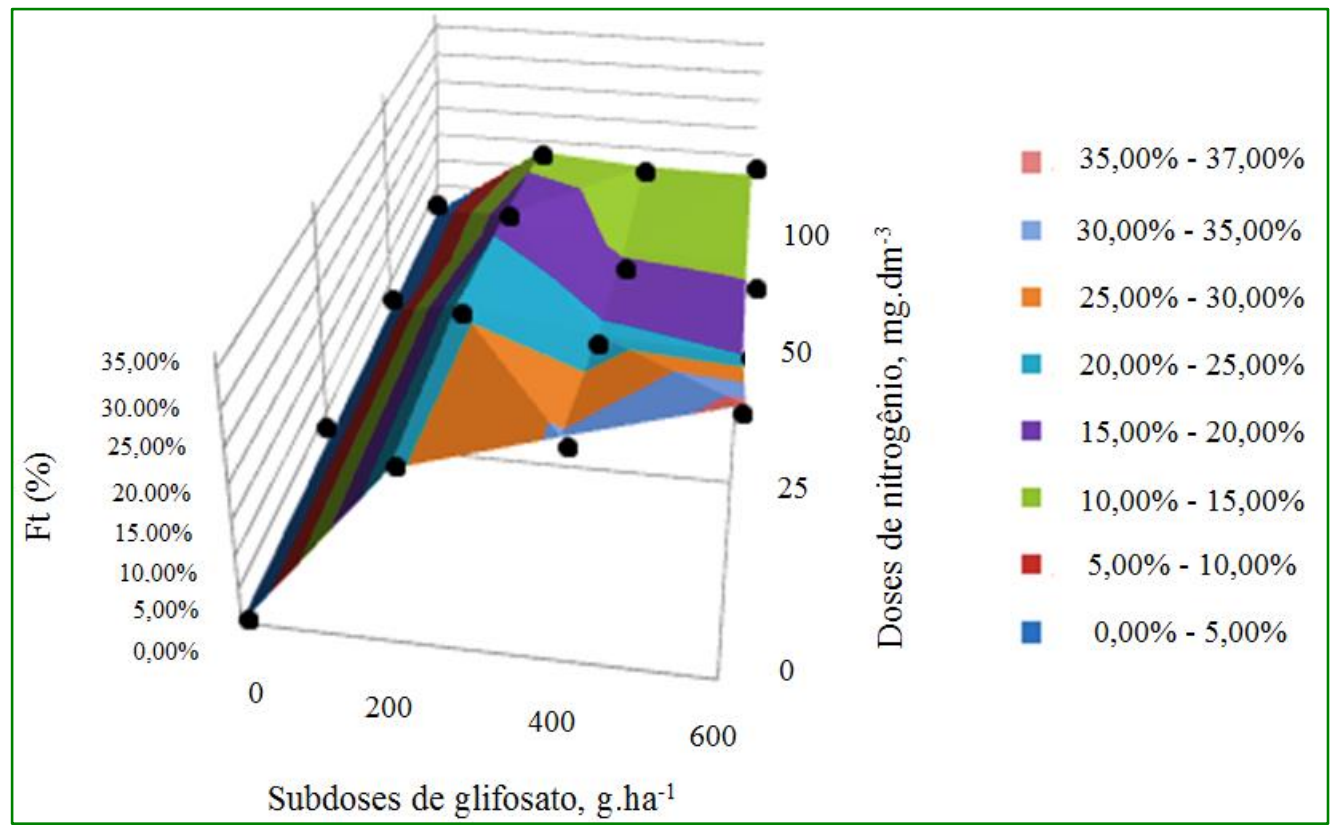

Fonte: Autores, 2015.

Tabela 4 - Doses de nitrogênio em função das subdoses de glifosato aos 44 DAP (REGISTRO, SP, 2015).

\begin{tabular}{|c|c|c|c|c|}
\hline Doses & & Máx & Min & Regressão \\
\hline 0 & $\hat{y}=0,008+0,001 x-1 E-06^{\star * *} x 2$ & 551 & & $<0,0001 Q$ \\
\hline 25 & $\hat{y}=0,014+0,001 x-2 E-06^{* * *} x 2$ & 400 & & $<0,0001 Q$ \\
\hline 50 & $\hat{y}=0,013+0,000 x-1 E-06^{* * *} x 2$ & 375 & & $<0,0001 Q$ \\
\hline 100 & $\hat{y}=0,007+0,000 x-8 E-07^{* \star *} x 2$ & 400 & & $0,0002 Q$ \\
\hline \multicolumn{5}{|c|}{ Subdose } \\
\hline 0 & Ns & & & Ns \\
\hline 200 & $\hat{y}=0,25266640-0,00121333^{* * *} x$ & & & $<0,0001 \mathrm{~L}$ \\
\hline 400 & $\hat{y}=0,307-0,004 x+3 E-05^{\star * *} x 2$ & & 86 & $0,0008 Q$ \\
\hline 600 & $\hat{y}=0,361-0,007 x+5 E-05^{* * *} x 2$ & & 77 & $<0,0001 Q$ \\
\hline
\end{tabular}

ns -não significativo; L e Q - linear e quadrático respectivamente; * 0,$05 ;{ }^{* \star}-<0,05 ;{ }^{\star \star \star}{ }^{*}<0,01$ Fonte: Autores, 2015.

Aos 52 DAP não houve interação entre doses de nitrogênio e subdoses de Glifosato (Tabela 2). As médias observadas com as doses de $\mathrm{N}$ obtiveram resultados lineares decrescentes com o menor valor de Ft observado com a maior dose de N (9\%) (Figura 3). Resultados semelhantes foram encontrados por Godoy et al. (2012) que evidenciam uma maior cobertura verde em gramados com alta dosagem de nitrogênio em cobertura. 
Fitotoxidez e taxa de cobertura verde de gramado bermuda submetido a dosagens de nitrogênio ...

Figura 3 - Fitoxidez (\%) de grama bermuda submetidas às doses de nitrogênio aos 52 DAP ${ }^{* * *}$ significativo $<0,01)$ (REGISTRO, SP, 2015).

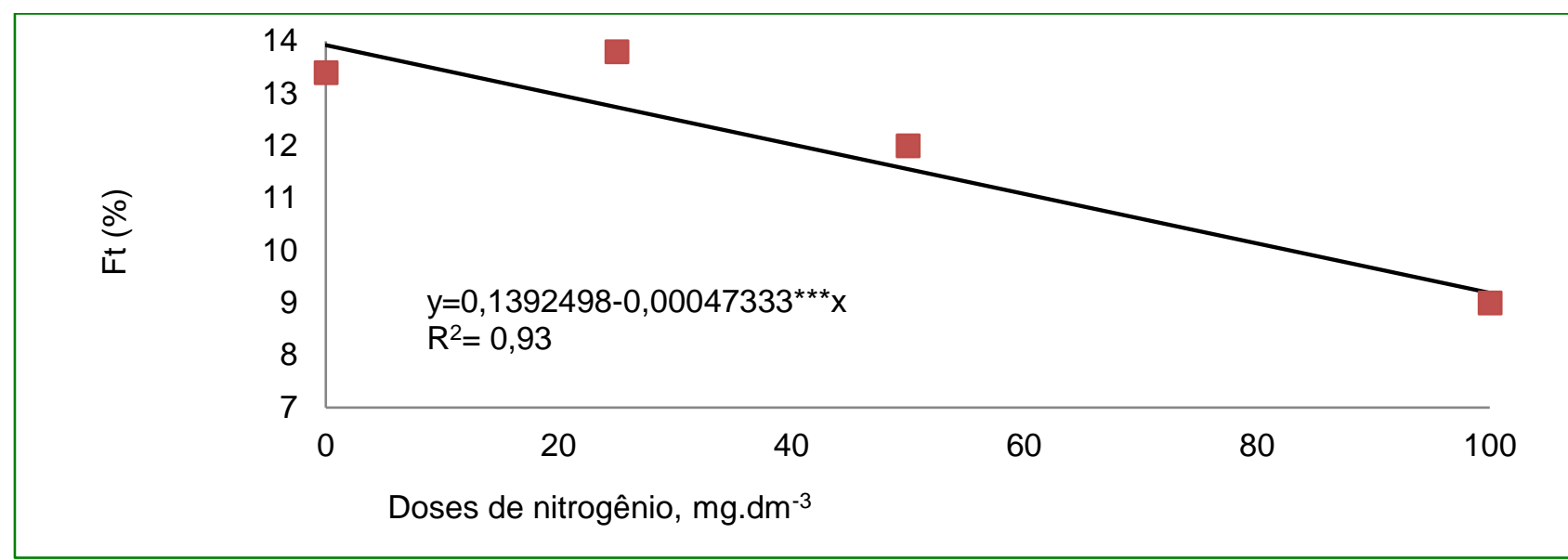

Fonte: Autores, 2015.

Já as médias observadas com as subdoses de Glifosato obtiveram resultados quadráticos crescentes onde houve um maior valor de Ft com a subdoses de $400 \mathrm{~g} \mathrm{ha}^{-1}$ de glifosato (16\%) (Figura 4). Observando as médias das três análises (35, 44 e 52 DAP) observou-se que aos 52 DAP houve uma diminuição de Ft mostrando uma recuperação do gramado.

Com relação a taxa de cobertura verde (TCV) não houve interação significativa entre os fatores, entretanto houve efeito das doses de $\mathrm{N}$ e das subdoses de glifosato aos 35 e 52 DAP (Tabela 5).

Os dados coletados aos 44 DAP não apresentaram resultados significativos (Tabela 5).Aos 35 e 52 observou-se nas maiores doses de $\mathrm{N}$, as maiores médias da taxa de cobertura verde, onde a dose de $100 \mathrm{mg} \mathrm{dm}^{-3}$ de nitrogênio proporcionou as maiores médias (0,83 e 0,62, respectivamente), (Figura 5), demostrando que quanto maior a dose de nitrogênio maior a taxa de cobertura verde (GODOY et al., 2007). 
Figura 4 - Fitoxidez (\%) de grama bermuda submetidas às subdoses de glifosato aos 52 DAP (***significativo $<0,01)$ (REGISTRO, SP, 2015).

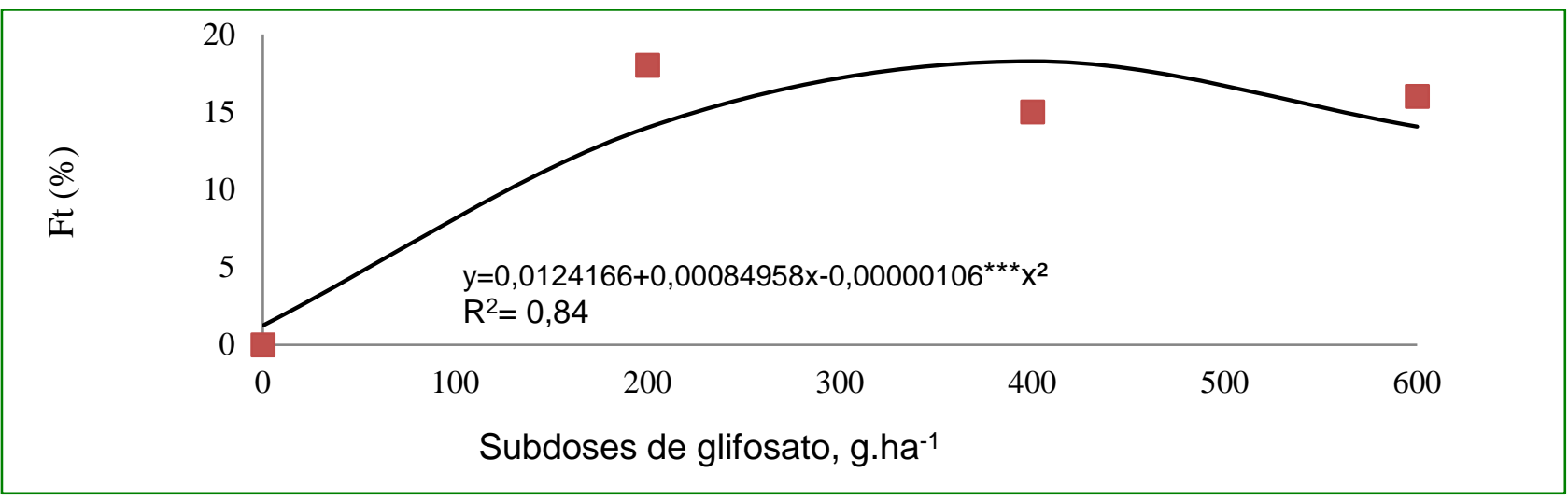

Fonte: Autores, 2015.

Figura 5 - TCV submetidas às doses de nitrogênio aos $35(A)$ e 52 (B) DAP $\left({ }^{* * *}\right.$ significativo $\left.<0,01\right)$ (REGISTRO, SP, 2015).

A

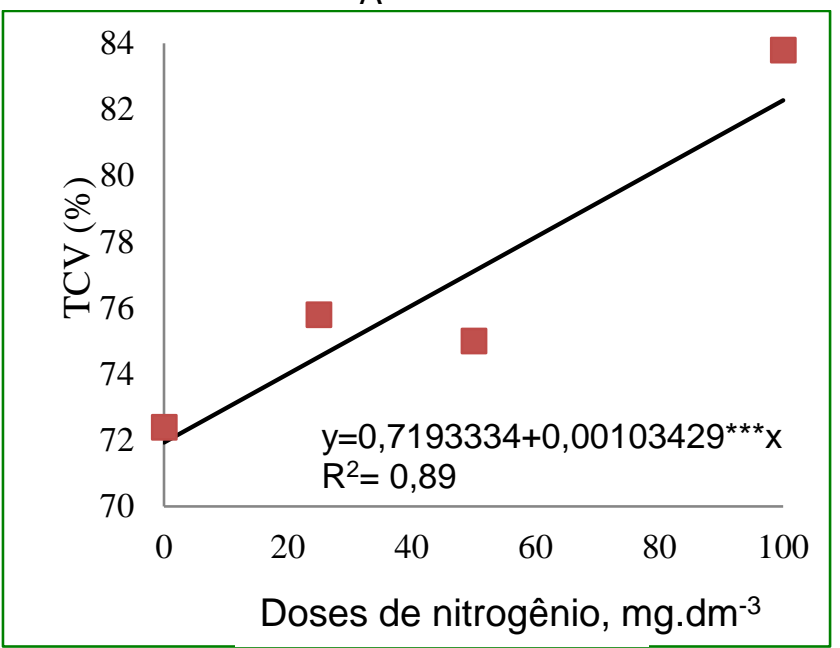

B

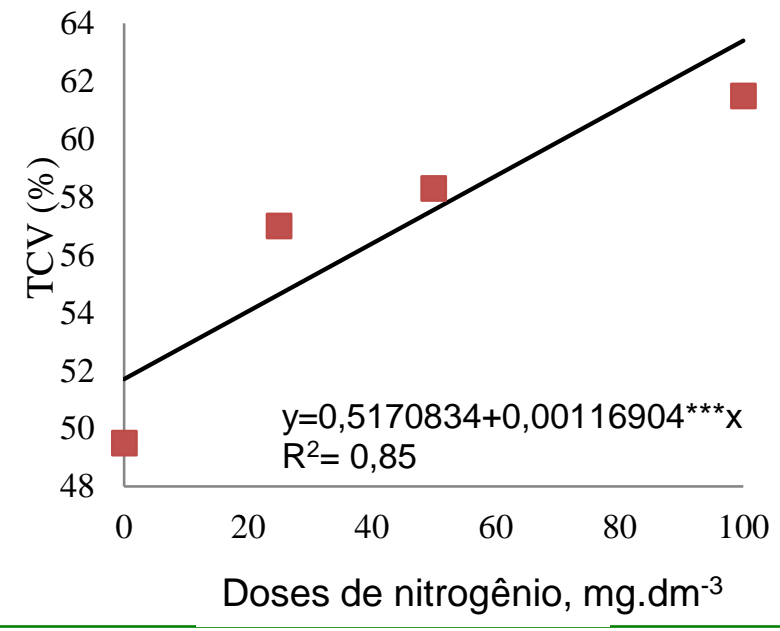

Fonte: Autores, 2015.

Para os dados de TCV das gramas submetidas às subdoses de glifosato, as médias observadas aos 35 DAP mostraram-se decrescentes linearmente à medida que as subdoses de glifosato foram aumentando. Já aos 52 DAP, os dados mostraram-se opostos aos dados analisados aos 35 DAP (Figura 6). Uma possível causa para explicar este resultado é a menor exportação de nitrogênio pela folha aos tratamentos submetidos a maiores subdoses de glifosato. Segundo Rodrigues et al., (2004), fitorreguladores podem aumentar a densidade e as reservas de nutrientes, o que explica a maior taxa de cobertura verde aos 52 DAP com as maiores doses de glifosato. 
Fitotoxidez e taxa de cobertura verde de gramado bermuda submetido a dosagens de nitrogênio ...

Tabela 5 - Resumo da análise estatística da taxa de cobertura verde (TCV), aos 35, 44 e 52 DAP (REGISTRO, SP, 2015).

\begin{tabular}{|c|c|c|c|}
\hline & 35 DAP & 44 DAP & 52 DAP \\
\hline Fator de Variação & & $\begin{array}{l}\text { CV } \\
\text { ralor }\end{array}$ & \\
\hline Dose $(\mathrm{N})$ & $<0,0027$ & 0,3652 & $<0,0001$ \\
\hline Subdose (G) & $<0,0069$ & 0,0684 & 0,0188 \\
\hline$N * G$ & 0,1906 & 0,3759 & 0,1279 \\
\hline C.V. \% & 13,26 & 20,34 & 15,50 \\
\hline Regressão (N) & $0,0004 \mathrm{~L}$ & ns & $<0,0001 L$ \\
\hline Regressão (G) & $0,0028 \mathrm{~L}$ & ns & $0,0028 \mathrm{~L}$ \\
\hline
\end{tabular}

C.V. - coeficiente de variação (\%); DAP- dias após o plantio; L e Q - linear e quadrático, respectivamente; ns- não significativo.

Fonte: Autores, 2015.

Figura 6 - TCV submetidas às subdoses de glifosato aos 35 (A) e 52 (B) DAP $\left({ }^{* * *}\right.$ significativo $\left.<0,01\right)$

A

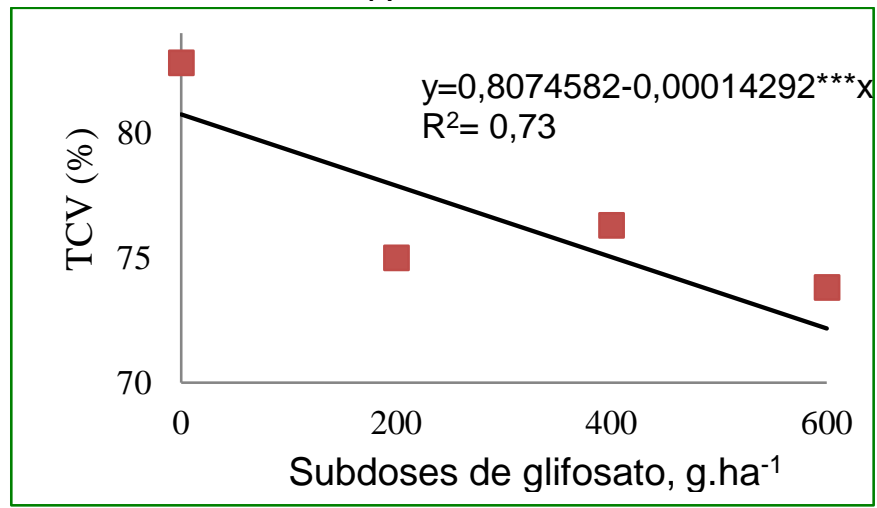

B

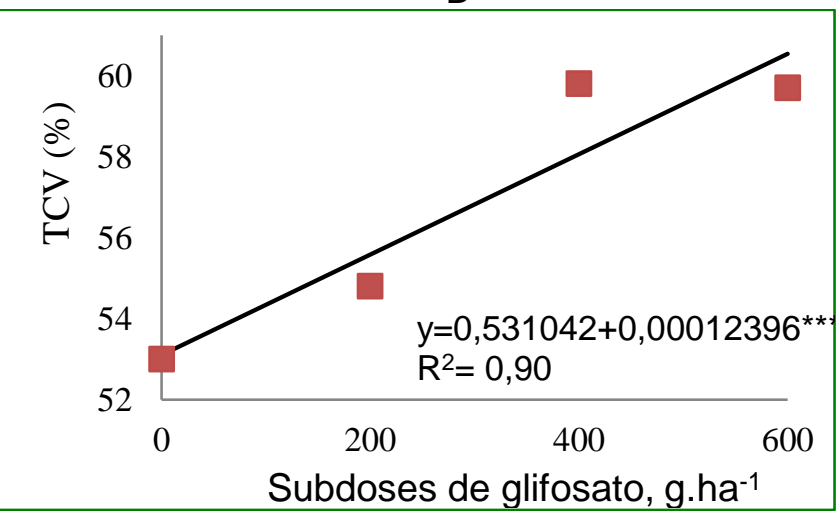

Fonte: Autores, 2015.

\section{CONCLUSÕES}

A aplicação do glifosato é viável no controle de crescimento do gramado bermuda desde que o mesmo apresente adubação eficiente em Nitrogênio.

O acréscimo de dosagens de nitrogênio propicia maior desenvolvimento do gramado bermuda.

A subdose e doses que causaram maior fitotoxidez foi de $429 \mathrm{~g} \mathrm{ha}^{-1}$ de glifosato e $0 \mathrm{e}$ $25 \mathrm{mg} \mathrm{dm}^{-3}$ de nitrogênio.

A subdose e dose que obteve maior taxa de cobertura foi de $400 \mathrm{~g} \mathrm{ha}^{-1}$ de glifosato $\mathrm{e}$ $100 \mathrm{mg} \mathrm{dm}^{-3}$ de nitrogênio. 
Conclui-se que a subdose de glifosato que mais se adequou como fitorregulador de crescimento, foi a de $432 \mathrm{~g} \mathrm{ha}^{-1}$ juntamente com doses de $100 \mathrm{mg} \mathrm{dm}^{-3}$ de nitrogênio para uma melhor qualidade do gramado.

\section{REFERÊNCIAS}

GAZOLA, R. P. D. Adubação nitrogenada e doses do herbicida glyphosate como regulador de crescimento em grama esmeralda. 2017. Tese (Doutorado em Agronomia - Sistemas de produção) - Faculdade de Engenharia, Universidade Estadual PAulista, Ilha Solteira, 2017. Disponível em:https://repositorio.unesp.br/bitstream/handle/11449/150612/gazola_rpd_dr_ilha.pdf?se quence $=5$ \&isAllowed=y>. Acesso em: 25 nov. 2020 .

GAZOLA, R. P. D.; BUZETTI, S.; GAZOLA, R. N.; CASTILHO, R. M. M.; TEIXEIRA FILHO, M. C. M.; CELESTRINO, T. S.; DUPAS, E. Nitrogen dose and type of herbicide used for growth regulation on the green coloration intensity of Emerald grass. Ciência Rural, v.46, p.984-990, 2016.

GODOY, L. J. G. Adubação nitrogenada para produção de tapetes de grama santo agostinho e esmeralda. 2005, 106p. Tese (Doutorado em Agronomia/Agricultura) Faculdade de Ciências Agronômicas, UNESP, Botucatu, SP, 2005.

GODOY, L. J. G.; VILLAS BÔAS, R. L. Tecnologias para auxiliar o manejo da aduba-ção na produção de gramas. In:V SIGRA - Simpósio de Gramados Anais... UNESP Faculdade de Ciências Agronômicas, Botucatu, SP, 2010.

GODOY, L. J. G.; VILLAS BÔAS, R. L.; BACKES, C.; LIMA, C. P. Doses de nitrogênio e potássio na produção de grama esmeralda. Ciência e Agrotecnologia, Lavras, v. 31, n. 5, p. 1326-1332, 2007.

GODOY, L. J. G.; VILLAS BÔAS, R. L.; BACKES, C. Produção de tapetes de grama Santo Agostinho submetida a doses de nitrogênio. Semina: Ciências Agrárias, v.33, p.1703-1716, 2012.

GURGEL, R.A.G. Principais espécies e variedades de grama. In: SIMPÓSIO SOBRE GRAMADOS, 1, 2003, Botucatu. Produção, implantação e manutenção: Anais. Botucatu: Departamento de Recursos Naturais, Faculdade de Ciências Agronômicas, Universidade Estadual Paulista, 2003.

LAURETTI, R. L. Implantação de gramados por sementes In: SIMPÓSIO SOBRE GRAMADOS, 1, 2003, Botucatu. Produção, implantação e manutenção: Anais. Botucatu: Departamento de Recursos Naturais, Faculdade de Ciências Agronômicas, Universidade Estadual Paulista, 2003.

NEVES, D. C. Efeito da aplicação de subdoses de glifosato em algodoeiro. 2009. 51 f. Monografia (Graduação em Agronomia) - Faculdade de Engenharia de llha Solteira, Universidade Estadual Paulista, Ilha Solteira, 2009. 
OLIVEIRA JUNIOR, R. S. Mecanismo de ação de herbicidas. In: OLIVEIRA JUNIOR, R. S.; CONSTANTIN, J.; INOUE, M. H. (Coord.). Biologia e manejo de plantas daninhas. Curitiba: Omnipax, 2011. p. 141-192.

RAIJ, B., ANDRADE, J.C., CANTARELLA, H., QUAGGIO, J.A. Análises químicas para avaliação da fertilidade de solos tropicais. Campinas: IAC/FUNDAG, 2001, 285p.

RODRIGUES, B. N. Guia de herbicidas. Londrina, PR, Quarta Edição, 1998. 646 p

RODRIGUES, J. D.; GODOY, L. J. G.; ONO, E. O. Reguladores vegetais: bases e princípios para utilização em gramados. In: II SIGRA - Simpósio Sobre Gramados "Manejo de Gramas na Produção e em Gramados Formados", 2, 2004, Botucatu. Anais... Botucatu: FCA/Unesp, 2004. 30p.

SANTOS, P. L. F. Substratos no desenvolvimento da grama bermuda e sub-doses de glyphosate como regulador de crescimento. Ilha Solteira, 2018. $69 \mathrm{f}$.

SANTOS, P. L. F.; CASTILHO, R. M. M. Caracterização físico-química de diferentes substratos e sua influência no desenvolvimento da grama esmeralda. Tecnologia \& Ciência Agropecuária, João Pessoa, v. 10, n. 6, p. 21-26, 2016. Disponível em: https://revistatca.pb.gov.br/edicoes/volume-10-2016/v-10-n-6-dezembro2016/tca10604.pdf. Acesso em: 25 nov. 2020.

SOCIEDADE BRASILEIRA DA CIÊNCIA DAS PLANTAS DANINHAS - SBCPD Procedimentos para instalação, avaliação e análise de experimentos com herbicidas. Londrina: SBCPD, 1995. 42 p.

TAIZ, L.; ZEIGER, E; MOLLER, M. I; MURPHY, A. Fisiologia vegetal. 6.ed. Porto Alegre: Artmed, 858p, 2017. 


\section{ABSTRACT}

The present work had as objective to evaluatedosages of glyphosate and nitrogen in the rate of green cover and in the rate of phytotoxicity by image of Bermuda lawn in tropical conditions. A completely randomized design with six replications was adopted. The treatments were done in a $4 \times 4$ factorial scheme, with four sub-doses of glyphosate $(0,200$, 400 and $600 \mathrm{~g}$ ha- 1 of ia), and four doses of nitrogen (0,25, 50 and $100 \mathrm{mg} \mathrm{dm}-3)$. The nitrogen was performed manually at 27 days after planting (DAP), with $100 \mathrm{ml}$ of water solution with urea, in the doses of $0,167,333$ and $667 \mathrm{mg}$ for each $100 \mathrm{ml}$ of water. The glyphosate underdose was performed with a manual pressure sprayer with a working pressure of $45 \mathrm{psi}$. The herbicide used was Roundup transorb, with i.a (glyphosate) of 480 $\mathrm{g} \mathrm{L}-1$. The percentages of phytointoxication were determined by digital images according to the green coverage rate methodology. The green coverage rate and the phytotoxicity rate were evaluated with the aid of the Corew Draw ${ }^{\circledR}$ imaging software. It was concluded that the sub-dose of glyphosate that best suited as a growth regulator was $432 \mathrm{~g}$ ha-1 with doses of $100 \mathrm{mg} \mathrm{dm}-3$ of nitrogen for a better quality of the lawn. The application of glyphosate is feasible in the growth control of the Bermuda lawn as long as it presents an efficient fertilization in Nitrogen. The addition of nitrogen dosages provides further development of the Bermuda lawn.

Keywords: Bermuda-grass. Growth regulator. Lawn Nutrition. Fertilizing.

\section{RESUMEN}

Este trabajo tuvo como objetivo evaluar dosis de glifosato y de nitrógeno en la tasa de cobertura verde y en la tasa de fitotoxidad por imagen de gramado bermuda en condiciones tropicales. Se adoptó el delineamiento experimental totalmente casualizado con seis repeticiones. Los tratamientos fueron hechos en esquema factorial $4 \times 4$, siendo cuatro subdosis de glifosato $\left(0,200,400\right.$ y $600 \mathrm{~g} \mathrm{ha}^{-1}$ del i.a.), y cuatro doses de nitrógeno $(0,25,50$ y $100 \mathrm{mg} \mathrm{dm}^{-3}$ ). El nitrógeno fue aplicado manualmente a los 27 días después del plantío (DDP), con $100 \mathrm{ml}$ de solución de agua con urea, en dosis de 0, 167, 333 y $667 \mathrm{mg}$ para cada $100 \mathrm{ml}$ de agua. El glifosato fue aplicado con pulverizador manual de presión previa con presión de trabajo de 45 psi. El herbicida utilizado fue Roundup transorb, con i.a (glifosato) de $480 \mathrm{~g} \mathrm{~L}^{-1}$. Los porcentajes de fito-intoxicación fueron determinados por imágenes digitales conforme metodología para tasa de cobertura verde. Fueron evaluadas la tasa de cobertura verde y la tasa de fitotoxicidad con el auxilio del software de imágenes Corew Draw ${ }^{\circledR}$. Se concluyó que la sub-dosis de glifosato que se adecuo más como fitoregulador de crecimiento, fue la de $432 \mathrm{~g} \mathrm{ha}^{-1}$ juntamente con la dosis de $100 \mathrm{mg} \mathrm{dm}^{-3} \mathrm{de}$ nitrógeno para una mejor calidad del gramado. La aplicación del glifosato es viable en el control de crecimiento del gramado bermuda desde que este presente fertilización eficiente en Nitrógeno. Aumentar las dosis de nitrógeno propicia mayor desarrollo de gramado bermuda.

Palabras clave: Grama-Bermuda. Nutrición de Gramas. Regulador de Crecimiento. Fertilización. 


\section{(EIOENG \\ Revista Brasileira de Engenharia de Biossistemas

\section{LICENÇA DE USO}

Este é um artigo publicado em acesso aberto (Open Access) sob a licença Creative Commons Atribuição 4.0 Internacional (CC BY 4.0), que permite uso, distribuição e reprodução em qualquer meio, desde que o trabalho original seja corretamente citado. Mais informações em: http://creativecommons.org/licenses/by/4.0

\section{CONFLITO DE INTERESSES}

Os autores declaram que não há conflito de interesses neste trabalho.

\section{CONTRIBUIÇÕES AUTORAIS}

Maria Clara Lelles Moreira Begueline: Responsável pelo experimento e autoria de todo o texto.

Leandro Garcia Alfonsi: Responsável pelo experimento.

Kamila Cristina de Credo Assis: Responsável pela análise de dados.

Leandro José Grava de Godoy: Responsável pela análise de dados e escrita do texto. João Victor Costa: Responsável pela análise de dados e orientação do experimento.

\section{FINANCIAMENTO}

O presente trabalho não contou com apoio financeiro.

\section{COMO REFERENCIAR}

BEGUELINE, Maria Clara Lelles Moreira; ALFONSI, Leandro Garcia Alfonsi; ASSIS, Kamila Cristina de Credo; de GODOY, Leandro José Grava; COSTA, João Victor. Fitotoxidez e taxa de cobertura verde de gramado bermuda submetido a dosagens de nitrogênio e glifosato. Revista Brasileira de Engenharia de Biossistemas (Tupã), v. 15, n. 1, p. 27-41, 2021. DOI: http://dx.doi.org/10.18011/bioeng2021v15n1p27-41.

\section{RESPONSABILIBADE EDITORIAL}

Prof. Dr. Fernando Ferrari Putti ${ }^{1}$, Prof. Dr. Paulo Sérgio Barbosa dos Santos ${ }^{1}$, Prof. Dr. Eduardo Festozo Vicente ${ }^{1}$ e Prof. Dr. Diogo de Lucca Sartori ${ }^{1}$

1 Universidade Estadual Paulista "Júlio de Mesquita Filho", FCE - Faculdade de Ciências e Engenharia, Tupã, SP, Brasil. 